\title{
Unemployment, Factor Substitution and Capital Formation
}

\author{
Leo Kaas \\ University of Vienna
}

\author{
Leopold von Thadden \\ Deutsche Bundesbank
}

\begin{abstract}
We incorporate a wage-bargaining structure in a dynamic general equilibrium model and show how this feature changes short- and long-run properties of equilibria compared with a perfectly competitive setting. We discuss how employment, capital and income shares respond to wage-setting shocks and show that adjustment dynamics depend decisively on the magnitude of the elasticity of substitution between labour and capital. Values of the elasticity below unity add persistence, tend to preserve stability and lead to empirically plausible adjustment patterns. By contrast, values above unity introduce additional volatility, thereby making steady states potentially unstable.
\end{abstract}

JEL classification: D51, E24, E25.

Keywords: Wage bargaining; unemployment; overlapping generations.

\section{INTRODUCTION}

This paper is motivated by the persistently high unemployment rates and modest investment dynamics in many European countries over the past decades, as recently summarized, for example, by Blanchard $(1997,1998)$ and Daveri and Tabellini (2000). To address this twin observation, we analyse the general equilibrium effects of wage-setting shocks in an economy with wage bargaining, unemployment and capital accumulation. As has been emphasized in previous literature (e.g. Bean, 1989; Burda, 1988; Benassy, 1997; Caballero and Hammour, 1998), the endogenous response of capital to wagesetting or technology shocks can serve as an important propagation mechanism for persistent employment dynamics. In particular, attempts by unions to raise wages are likely to trigger an investment slow-down in order to restore the initial level of profitability, and, as a by-product, the adverse impact effect on employment may be further exacerbated. Evidently, the strength and direction of the interaction between labour and capital depends 
critically on the degree of substitutability between these two factors in the production function. As we discuss in Section 6, the empirical literature is very ambivalent as to how the elasticity of substitution should be specified, and also the theoretical literature is based on diverse assumptions. ${ }^{1}$

The main purpose of this paper is to establish a framework in which the properties of short-run and long-run equilibria and the economy's response to wage-setting shocks can be explicitly linked to the magnitude of the elasticity of substitution. To this end, we consider a standard overlapping-generations growth model that is augmented by wage bargaining and unemployment, assuming a traditional neoclassical production function with an unrestricted elasticity of substitution between labour and capital. We assume a right-tomanage set-up where sector-specific unions and employers' federations bargain on behalf of a large set of firms and workers over wages which are mandatory for all employment contracts. In every period, taking the sector-wide capital stock as given, the two sides decide on the wage, and individual firms then have full discretion over the level of employment. Employment in the representative sector depends on the bargaining power of the two sides, the value of the reservation wage maintained during the bargain by the union, and - as the key characteristic of short-run equilibria - on the location of the labour demand curve which is parametrized by the prevailing level of the capital stock.

Over time, however, the capital stock changes, and long-run equilibria in our bargaining model can be conveniently characterized relative to a set-up with a perfectly competitive labour market. In particular, assuming that in general equilibrium all unemployment benefits are funded through taxes on labour, we establish for homothetic preferences that the long-run stationary capital intensity will be identical to the one resulting under perfectly competitive labour markets. Thus, shocks affecting long-run employment translate into proportional changes in the capital stock, and properties of long-run equilibria can be directly compared with steady states of perfectly competitive overlapping-generations models as discussed, for example, in Galor and Ryder (1989) and Azariadis (1993).

Leaving the elasticity of substitution $\sigma$ between labour and capital a priori unrestricted, it turns out that, depending on this elasticity, short-run properties of equilibria and off-steady-state dynamics are much richer than in the fully competitive framework. If $\sigma<1$ there is, under plausible conditions, a unique short-run equilibrium, and long-run steady states will be stable whenever they are stable in the benchmark case of full employment dynamics. In particular, shocks affecting the labour market (such as a shift in relative bargaining power or changes in the replacement rate) create

1. Static bargaining models often follow the benchmark established in Layard et al. (1991) and set the elasticity of substitution $\sigma=1$. Under standard assumptions this implies that the employment level will be independent of the capital stock. For $\sigma \neq 1$ this is no longer the case, but, as we show in Section 6, the literature disagrees on whether $\sigma$ should be specified as being smaller or larger than unity. 
persistent employment dynamics. By contrast, if $\sigma>1$ uniqueness of shortrun equilibria is no longer assured, and due to strong substitution effects the stability correspondence between full employment and unemployment dynamics breaks down. This creates the possibility of unstable steady states and endogenous cycles. Moreover, even if one restricts the analysis to stable steady-state states, wage-setting shocks imply an empirically implausible initial over-shooting of employment. In Section 6, we also link our model to the recent debate on shifts in income shares in various continental European countries (Blanchard, 1997, 1998). Again we confirm that $\sigma<1$ leads to empirically plausible adjustment processes, while the evolution of income shares implied by $\sigma>1$ is not consistent with the empirical evidence. Finally, we establish that our results are not confined to overlapping-generations economies, but apply also, for example, in the context of a Solow growth model when augmented appropriately by wage bargaining.

In related work, Daveri and Tabellini (2000), also using a Diamond-type overlapping-generations (OLG) economy, discuss the dynamic effects of wages, which are set by small and sector-specific unions, on investment and growth. Essentially, the model shows that low employment may well slow down investment dynamics via reduced savings. However, the complementary argument stressed in our framework ('reduced investment dynamics after a wage shock as a propagation mechanism for low employment') is absent from their analysis, because employment is specified as being independent of the capital stock. Benassy (1997) investigates adjustment dynamics around full employment steady states in an OLG economy with stochastic lifetimes, monopolistic wage setting and an aggregate production function with $\sigma<1$. The degree of persistence of adjustment dynamics depends crucially on whether wages set by the monopoly union become binding or not. In particular, in the spirit of some of our results, when union wages become binding, the corresponding unemployment dynamics show pronounced persistence. ${ }^{2}$ Also related is the model of Devereux and Lockwood (1991), who embed union-firm wage bargaining in a Diamond growth model to stress the importance of binding versus non-binding wage agreements on investment. However, using efficient wage bargaining (as opposed to the right-to-manage framework of our paper) and abstracting from disutility of labour, labour must be fully employed and, consequently, there is no link between an investment slow-down and unemployment dynamics.

The remainder of the paper proceeds as follows. In Section 2 we describe the details of the model. Section 3 characterizes the short-run equilibrium when the capital stock is given. In Section 4 we turn to the dynamic behaviour of the model. Section 5 analyses the adjustment dynamics resulting from increased wage pressure, while Section 6 discusses our results in the context of further literature. The final section concludes with a summary.

2. In Section 4, we discuss how our stability results relate to the model of Benassy. 


\section{THE MODEL}

Consider an overlapping-generations economy which consists of a large number $M$ of sectors, a continuum $[0, M]$ of consumers/workers living for two periods and a continuum $[0, M]$ of firms. Consumers supply labour when they are young and consume in both lifetime periods. Firms produce a composite consumption/investment good from inputs of capital and labour. The government pays an unemployment benefit which is financed by a wage income tax. The capital and goods markets are perfectly competitive, but wages are the outcome of a bargain between trade unions and employers' federations at the sector level. In each sector, a single trade union representing a mass 1 of (risk-averse) workers and a single employers' federation representing a mass 1 of (risk-neutral) firms bargain over the wage which is mandatory for all work relationships in that sector. Since the number of sectors is large, negotiation partners ignore the effect of their decision on the unemployment rate and on the level of unemployment benefits. ${ }^{3}$ After wages are negotiated, employment is decided at the level of the firm ('rightto-manage model'). ${ }^{4}$ Since each employers' federation represents a large number of firms, the capital investment decision of any single firm does not affect the outcome of the wage bargain, and therefore all firms behave in a perfectly competitive fashion. In particular, there are no strategic aspects of wage setting vis-à-vis investment decisions, as discussed in the literature on the typical hold-up problem of firm-specific bargaining (Grout, 1984; Van der Ploeg, 1987; Devereux and Lockwood, 1991). Moreover, the overlappinggenerations specification addresses the difficult question of how to specify the attitude of institutions towards members of different generations in a particularly transparent way. Both unions and employers' federations bargain in every period only on behalf of agents belonging to a single generation, and since sectors are 'small', intertemporal considerations need not be taken into account. Finally, we also allow for worker turnover between sectors. As a consequence, wages paid in other sectors and the aggregate unemployment rate matter for wage formation in every sector. As will become clear below, this implies that any equilibrium involves some positive rate of unemployment. In detail, the economy is described as follows.

\subsection{Consumers}

Each consumer/worker born at date $t$ supplies one unit of indivisible labour when young and consumes in periods $t$ and $t+1$. Consumers save part of

3. Compared with centralized bargaining, in which a single union and a single employers' federation internalize the impact of their decisions on aggregate outcomes, this assumption tends to increase the unemployment rate (see, for example, Calmfors and Drifill, 1988).

4. For detailed treatments of this and alternative bargaining concepts in partial equilibrium, see McDonald and Solow (1981) and Oswald (1985). 
their labour income for retirement by holding capital shares, paying a gross real return rate $R_{t+1}$. An employed worker receives a real net wage $w_{t}\left(1-\tau_{t}\right)$ whereas an unemployed worker receives the real unemployment benefit $b_{t}$. Workers are randomly allocated to jobs. Their von Neumann-Morgenstern utility function $u\left(c_{t}, c_{t+1}\right)$ is assumed to be homothetic, strictly quasi-concave and differentiable. In particular, we assume $u$ to be homogeneous of degree $1-\gamma$ where $\gamma \in[0,1)$ is the worker's coefficient of constant relative risk aversion. Each consumer's savings behaviour is described by a savings function $s\left(R_{t+1}\right) I_{t}$ where $I_{t} \in\left\{w_{t}\left(1-\tau_{t}\right), b_{t}\right\}$ denotes the first-period income, and the consumer's indirect utility is $v\left(R_{t+1}\right) I_{t}^{1-\gamma}$ where $v\left(R_{t+1}\right) \equiv$ $u\left(1-s\left(R_{t+1}\right), s\left(R_{t+1}\right) R_{t+1}\right)$. We assume that dated consumption goods are gross substitutes so that $s^{\prime} \geq 0$, i.e. savings are non-decreasing in the interest rate.

\subsection{Trade unions}

Each trade union represents a continuum of mass 1 of workers (union members). We assume that workers are attached to their home sector in the first place, but that they may seek employment in some other sector if they do not find employment in their home sector. To model turnover of workers between sectors, we assume that there are idiosyncratic productivity shocks (to capture worker-firm-specific mismatch) breaking up a fraction of the initially created work relationships. Whenever such a shock occurs, the worker seeks employment somewhere else in the economy and the firm attempts to fill the vacancy with some unemployed worker from some other sector. ${ }^{5}$ Specifically, we assume that a fraction $0<\pi<1$ of the initially created work relationships turns out to be unproductive. These relationships are separated immediately, i.e. if $L_{t} \leq 1$ jobs are created in some sector, a fraction $\pi L_{t}$ of these jobs is eventually not matched with workers of the home sector, but is filled with workers of some other sector. Thus $(1-\pi) L_{t}$ workers receive the negotiated sector net wage $w_{t}\left(1-\tau_{t}\right)$, and $1-(1-\pi) L_{t}$ workers are either employed in another sector or they remain unemployed. Their expected income, denoted $w_{t}^{*}$, will be determined below. The trade union anticipates the potential turnover of workers, and its objective is to maximize the expected utility of a representative member ${ }^{6}$ which is

$$
V_{t} \equiv v\left(R_{t+1}\right)\left((1-\pi) L_{t}\left(w_{t}\left(1-\tau_{t}\right)\right)^{1-\gamma}+\left(1-(1-\pi) L_{t}\right)\left(w_{t}^{*}\right)^{1-\gamma}\right)
$$

5. Other, more ad hoc, specifications of turnover in wage bargaining models can be found in Layard et al. (1991) and in Rowthorn (1999).

6. Note that, because of risk aversion, there is potential for Pareto-improving employment lotteries offered by trade unions. However, we assume, quite realistically in our view, that they are ruled out institutionally, so that governmental unemployment benefits represent the only means of insurance against unemployment risk in this economy. 
When negotiations break down, the union's fallback payoff is $\bar{V}_{t} \equiv$ $v\left(R_{t+1}\right)\left(w_{t}^{*}\right)^{1-\gamma}$, and thus the union surplus of a successful negotiation is

$$
V_{t}-\bar{V}_{t}=v\left(R_{t+1}\right)(1-\pi)\left(\left(w_{t}\left(1-\tau_{t}\right)\right)^{1-\gamma}-\left(w_{t}^{*}\right)^{1-\gamma}\right) L_{t}
$$

\subsection{Firms and employers' federations}

Firms produce the output good from capital and labour using the constant returns production technology $Y_{t}=F\left(K_{t}, L_{t}\right)=L_{t} f\left(k_{t}\right)$ where $k_{t}=K_{t} / L_{t}$ is the capital intensity. The intensive-form production function $f$ is increasing and strictly concave. Capital investment is decided a period in advance and thus before wages are negotiated. However, since the investment decision of any single firm has a negligible effect on the total capital stock and thus on labour demand in its sector, firms ignore the impact of their investment decision on the outcome of wage negotiations. Thus firms take the (perfectly foreseen) wage and the interest rate as given, which implies the usual marginality conditions

$$
w_{t}=w\left(k_{t}\right) \equiv f\left(k_{t}\right)-k_{t} f^{\prime}\left(k_{t}\right) \quad \text { and } \quad R_{t}=R\left(k_{t}\right) \equiv 1-\delta+f^{\prime}\left(k_{t}\right)
$$

where $\delta$ is the depreciation rate. Firms of each sector are organized in an employers' federation whose objective is the profit of each of its members,

$$
\Pi_{t} \equiv F\left(K_{t}, L_{t}\right)-w_{t} L_{t}=\left(f\left(k_{t}\right)-w\left(k_{t}\right)\right) L_{t}=k_{t} f^{\prime}\left(k_{t}\right) L_{t}
$$

The fallback payoff of the employers' federation is $\bar{\Pi}_{t}=0$.

\subsection{The wage bargain}

Given a sector capital stock $K_{t}$, the trade union and the employers' federation negotiate the sector wage taking into account that employment is decided by firms. The large number of sectors implies that negotiation partners ignore the impact of their decision on capital formation and thereby on the capital return in the next period. In particular, unions take $R_{t+1}$ in their objective function as given. The outcome of the wage bargain is determined by the Nashbargaining solution which maximizes the Nash product $\left.\left(\Pi_{t}-\bar{\Pi}\right)_{t}\right)^{\beta}$ $\left(V_{t}-\bar{V}_{t}\right)^{1-\beta}$ subject to $w_{t}=w\left(K_{t} / L_{t}\right) . \beta \in[0,1]$ denotes the bargaining power of the employers' federation. Using (1), (2), $L_{t}=K_{t} / k_{t}$ and cancelling out constants, the Nash program can be reformulated in terms of the sector's capital intensity:

$$
\max _{k_{t} \geq K_{t}}\left(k_{t} f^{\prime}\left(k_{t}\right)\right)^{\beta}\left(\left(w\left(k_{t}\right)\left(1-\tau_{t}\right)\right)^{1-\gamma}-\left(w_{t}^{*}\right)^{1-\gamma}\right)^{1-\beta} k_{t}^{-1}
$$

The Nash product is zero at $k^{*}$ such that $w\left(k^{*}\right)\left(1-\tau_{t}\right)=w_{t}^{*}$ and it is zero at $k=\infty$ since $w(k) / k$ tends to zero as $k \rightarrow \infty$. We assume that the Nash product is strictly quasi-concave (which is satisfied, for example, for the CES cases considered below). Hence a maximum necessarily exists and an interior (or 
unemployment) solution of the Nash program is characterized by the firstorder condition ${ }^{7}$

$$
\beta \frac{f^{\prime \prime}\left(k_{t}\right) k_{t}}{f^{\prime}\left(k_{t}\right)}+(1-\beta)\left((1-\gamma) \frac{k_{t} w^{\prime}\left(k_{t}\right)}{w\left(k_{t}\right)} \frac{\left(w\left(k_{t}\right)\left(1-\tau_{t}\right)\right)^{1-\gamma}}{\left(w\left(k_{t}\right)\left(1-\tau_{t}\right)\right)^{1-\gamma}-\left(w_{t}^{*}\right)^{1-\gamma}}-1\right)=0
$$

Note that (3) implicitly balances three effects against each other, the first one with weight $\beta$, the other two with weight $1-\beta$. First, for given $K_{t}$ higher wages reduce profits by the factor price frontier, i.e. $f^{\prime}\left(k_{t}\right)$ and thus profits decline. Second, employed workers benefit from higher wages, i.e. $w_{t}\left(1-\tau_{t}\right)-w_{t}^{*}$ rises. Third, higher wages reduce employment and thus the surplus of the union.

\subsection{The general equilibrium}

Since the workers' outside option $w_{t}^{*}$ is the same in all sectors and since (3) has only one solution when the Nash product is strictly quasi-concave, employment and wages in all sectors coincide and the general equilibrium is symmetric. When $L_{t}$ is employment in each sector, $M\left(1-(1-\pi) L_{t}\right)$ workers in the economy are eventually not employed in their home sector. With a probability $\varphi_{t}$ each of them finds a job in some other sector. Given that there are $M \pi L_{t}$ vacancies left, this probability is

$$
\varphi_{t}=\frac{\pi L_{t}}{1-(1-\pi) L_{t}}
$$

The government maintains a constant replacement rate $\lambda<1$, which implies that the unemployment benefit is $b_{t}=\lambda w_{t}\left(1-\tau_{t}\right)$. Thus the expected income of a worker who is not employed in his home sector is

$$
w_{t}^{*}=\varphi_{t} w_{t}\left(1-\tau_{t}\right)+\left(1-\varphi_{t}\right) b_{t}=\left(\varphi_{t}+\lambda\left(1-\varphi_{t}\right)\right) w_{t}\left(1-\tau_{t}\right)
$$

Note that there cannot be full employment in general equilibrium. If $L_{t}=1$, all workers are employed with probability one, $\varphi_{t}=1$, and therefore the union's fallback payoff coincides with the net wage of the other sectors. Since any outcome of the wage bargain must pay some markup over the fallback wage whenever unions have bargaining power $(\beta<1)$, this wage cannot be set in equilibrium. Some unemployment is required to keep union wage demands in check.

Inserting (4) into (5) shows that the workers' outside wage is increasing in aggregate employment: the higher employment is, the more likely it is for an unemployed worker to find a job in some other sector. Combining this with the bargaining solution (3) and solving for employment yields a relation between (sector) employment and the capital intensity that has to hold in the

7. Below it will be shown that there can only be an unemployment outcome in general equilibrium, and that it is therefore sufficient to consider an interior solution. 
short-run (or temporary) equilibrium:

$$
L_{t}=L\left(k_{t}\right) \equiv \frac{\mu\left(k_{t}\right)-\lambda}{\pi+(1-\pi) \mu\left(k_{t}\right)-\lambda}
$$

where

$$
\mu(k) \equiv\left(1-\frac{(1-\beta)(1-\gamma) \frac{w^{\prime}(k) k}{w(k)}}{1-\beta\left(1+\frac{f^{\prime \prime}(k) k}{f^{\prime}(k)}\right)}\right)^{\frac{1}{1-\gamma}}
$$

provided that the term in the parenthesis is positive. The other equation that (trivially) holds in any equilibrium is

$$
L_{t}=K_{t} / k_{t}
$$

For a given capital stock $K_{t}$ equations (6) and (8) determine sector employment $L_{t}$ and the economy's capital intensity in period $t$. Equation (6) captures equilibrium in the labour market, whereas only (8) includes the capital stock. Finally, the government balances its budget by adjusting the tax rate so that $\tau_{t} w_{t} L_{t}=\lambda\left(1-\tau_{t}\right) w_{t}\left(1-L_{t}\right)$. This can always be achieved by a unique tax rate $\tau_{t}$ which, however, does not affect employment and the gross wage in our model. This result, which has also been demonstrated in a similar model by Pissarides (1998), depends on the assumption that the government fixes the replacement rate, i.e. the ratio of unemployment benefits to net wages. If, instead, the government did not adjust benefits to wages but fixed the level of (real) unemployment benefits, a higher income tax rate would unambiguously reduce employment.

\section{THE SHORT-RUN EQUILIBRIUM}

We concentrate in this section on CES production functions given by

$$
F(K, L)=\left[\alpha\left(A_{K} K\right)^{(\sigma-1) / \sigma}+(1-\alpha)\left(A_{L} L\right)^{(\sigma-1) / \sigma}\right]^{\sigma /(\sigma-1)} \quad 1 \neq \sigma>0
$$

which, in the boundary case $\sigma=1$, becomes a Cobb-Douglas production function $F(K, L)=A K^{\alpha} L^{1-\alpha}$. Existence, uniqueness and comparative statics properties of a short-run equilibrium depend crucially on the elasticity of substitution $\sigma$. The function (7) turns out to be

$$
\mu(k)=\left(1-\frac{(1-\beta)(1-\gamma) \alpha}{\sigma \alpha(1-\beta)+(\sigma(1-\beta)+\beta)(1-\alpha)\left(k A_{k} / A_{L}\right)^{-(\sigma-1) / \sigma}}\right)^{\frac{1}{1-\gamma}}
$$

In the Cobb-Douglas case $\mu(\cdot)$ is a constant,

$$
\mu=((\alpha \gamma(1-\beta)+1-\alpha) /(1-\alpha \beta))^{1 /(1-\gamma)}
$$

\section{2}




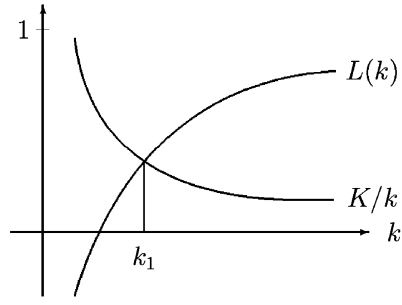

(a) $0<\sigma<1$

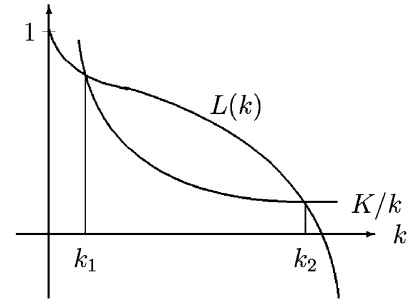

(b) $1<\sigma<\bar{\sigma}$

Figure 1 Short-run equilibrium

which is less than 1 . Whenever the replacement ratio is not too high, $\lambda<\mu$, there exists a short-run equilibrium with positive employment $(1>L(k)>0)$. The employment level in this case is independent of the capital stock, consistent with the findings of Layard et al. (1991).

More interesting results are obtained if the elasticity of substitution $\sigma$ is different from 1 . Consider first the case in which capital and labour are gross complements, $\sigma<1$. Then $\mu(k)$ is strictly increasing, as is $L(k)$. Moreover, $\mu(\infty)=1$ and thus $L(\infty)=1$. Figure 1a shows the two equilibrium curves (6) and (8) and reveals that there exists a unique short-run equilibrium $k_{1}$ for any level of the capital stock $K$. If the capital stock is increased, (8) shifts outwards and employment and the capital intensity (and thereby wages) increase.

Consider next gross substitutes, $\sigma>1$. Then $\mu(k)$ is strictly decreasing with $\mu(0)=1$. When $k \rightarrow \infty, \mu(k)^{1-\gamma}$ must tend to $1-(1-\gamma) / \sigma$. Whenever substitutability is not too strong, $\sigma<\bar{\sigma} \equiv(1-\gamma) /\left(1-\lambda^{1-\gamma}\right), \mu(k)$ equals $\lambda$ for some unique $\tilde{k}$. In this case, $L(k)$ is strictly decreasing with $L(0)=1$ and $L(\tilde{k})=0$. Figure $1 b$ shows the two equilibrium curves (6) and (8) in this case. It can be seen that there are two short-run equilibrium solutions, here denoted $k_{1}$ and $k_{2}$, whenever the capital stock is not too large. ${ }^{8}$ However, as will be shown in Proposition 2 below, only the left-hand equilibrium can occur in a stable steady state of the dynamic model, i.e. only the left short-run equilibrium can be a stable long-run equilibrium. A steady state at which the right equilibrium occurs would be unstable. We therefore consider below only the equilibrium $k_{1}$ at which (8) cuts (6) from above. If the elasticity of substitution is larger, $\sigma \geq \bar{\sigma}, L(k)$ is strictly positive for all capital intensities and tends to $\left(\mu_{\infty}-\lambda\right) /$ $\left((1-\pi) \mu_{\infty}+\pi-\lambda\right)$ as $k \rightarrow \infty$ where $\mu_{\infty}=(1-(1-\gamma) / \sigma)^{1 /(1-\gamma)}$. In this case there is only one short-run equilibrium $k_{1}$ at which (8) cuts (6) from above. In both cases, when the capital stock is increased, $k_{1}$ increases (and thus wages) and employment $L\left(k_{1}\right)$ falls, i.e. capital crowds out labour as a production factor, as one would expect under strong substitutability between capital and labour.

8. For CES production functions there are only two solutions, but in general there could be more than two solutions if the slope of the downward-sloping function $L(k)$ was sufficiently non-monotone. 
The findings of this section are summarized in the following proposition:

Proposition 1. Assume that the production function has constant elasticity of substitution $\sigma$. (a) If $\sigma<1$, there exists a unique short-run equilibrium for any level of the capital stock. Employment increases if the capital stock is increased. (b) If $1<\sigma<\bar{\sigma}$, there are two short-run equilibria when the capital stock is sufficiently low, and there is no short-run equilibrium if the capital stock is too large. (c) If $\sigma \geq \bar{\sigma}$, there is a unique short-run equilibrium solution. In both cases (b) and (c), employment falls if the capital stock is increased at the equilibrium with the lower capital intensity.

Finally, we find it worthwhile to point out that, regardless of the magnitude of $\sigma$, full employment equilibria could well emerge in the special case of no turnover, i.e. if one were to admit $\pi=0$. Assuming $\pi=0, L(k)$ becomes vertical at the value of $k$ which solves (3)-(5) (or equivalently $\mu(k)=\lambda$ ), and for $K$ being larger than this value, $L=1$ would turn into a binding restriction. In other words, given a fixed labour supply, full employment can emerge for $\pi=0$ if the outward shift of the labour-demand schedule induced by a rise in $K$ is sufficiently strong.

\section{DYNAMICS}

The total income of young consumers (employed and unemployed workers) equals

$$
M\left(1-\tau_{t}\right) w\left(k_{t}\right) L\left(k_{t}\right)+M \lambda\left(1-\tau_{t}\right) w\left(k_{t}\right)\left(1-L\left(k_{t}\right)\right)=M w\left(k_{t}\right) L\left(k_{t}\right)
$$

since the budget of the government is balanced. Because consumers have identical homothetic preferences, a fraction $s\left(R_{t+1}\right)$ of this income is saved as capital holdings giving the capital stock $M K_{t+1}$ of the next period. Using (8) and cancelling out $M$, we obtain the following dynamic equation describing the evolution of the capital intensity:

$$
k_{t+1} L\left(k_{t+1}\right)=s\left(R\left(k_{t+1}\right)\right) w\left(k_{t}\right) L\left(k_{t}\right)
$$

The dynamics of our model described by (9) can be related to the dynamics of the standard Diamond growth model with a competitive labour market. Indeed, when the labour market is perfectly competitive, labour is fully employed $(L=1)$, all workers are paid the wage $w\left(k_{t}\right)$ and the dynamic equation is

$$
k_{t+1}=s\left(R\left(k_{t+1}\right)\right) w\left(k_{t}\right)
$$

It follows immediately that in both models the steady-state capital intensity is determined by

$$
\bar{k}=s(R(\bar{k})) w(\bar{k})
$$

\section{4}


In particular, the steady-state capital intensity in the bargaining model with unemployment is independent of labour market conditions (union bargaining power, replacement ratio, turnover rate), but depends solely on technology (via $w$ and $R$ ) and on preferences (via $s$ ). A consequence of this result is that the gross wage and the interest rate in the steady state do not depend on labour market parameters, as well. Note that this result depends critically on the assumption that unemployment benefits are solely financed by taxes on labour and that preferences are homothetic. In the long run, changes in labour market conditions translate completely into changes of employment and of the capital stock, both in the same proportions. In terms of Figure 1, employment is determined at the intersection of (6) with the (not necessarily unique) stationary capital intensity $\bar{k}$, and dynamic adjustments to the steady state are described by shifts of (8). In the gross complements case (Figure 1a), capital and labour move in the same direction along an adjustment path to the steady state, whereas for gross substitutes $\left(k_{1}\right.$ in Figure $1 b$ ), employment falls when the capital stock increases, and vice versa.

It is well known from the analysis of the Diamond model with fully competitive labour markets that there can be multiple positive steady states. For instance, suppose that savings do not depend on the interest rate (which is the case if the intertemporal utility function is Cobb-Douglas) or, more generally, that the interest elasticity of savings is not too large. If the production function has CES $\sigma \geq 1$, there is only one positive steady state, as shown in Figure $2 \mathrm{~b}$. This steady state is globally stable in the full employment dynamics (10). But if $\sigma<1$, the equation has typically no or two positive solutions $\bar{k}_{a}$ and $\bar{k}_{b}$, as shown in Figure $2 \mathrm{a}$, of which the larger one is locally stable, whereas the other one is unstable in the full employment dynamics (10).

How does stability of steady states change in the unemployment dynamics (9)? Our main result is that stability features of steady states in the unemployment model and in the full employment model coincide when $\sigma<1$ (hence, in Figure 2, $\bar{k}_{a}$ is stable and $\bar{k}_{b}$ is unstable also in the unemployment dynamics). Labour market conditions do not matter in this case. But when $\sigma>1$, stability of the steady state depends critically on features of the short-run employment function $L(k)$. To see this, denote by $\eta_{h}(x) \equiv h^{\prime}(x) x / h(x)$ the elasticity of some function $h$ at $x$. Implicit differentiation of (9) at a steady state $\bar{k}$ yields

$$
d(\bar{k}) \equiv \frac{d k_{t+1}}{d k_{t}}(\bar{k})=\frac{\eta_{w}(\bar{k})+\eta_{L}(\bar{k})}{1+\eta_{L}(\bar{k})-\eta_{s}(R(\bar{k})) \eta_{R}(\bar{k})}
$$

From our assumptions on the production function and the savings function we have

$$
\eta_{w}(\bar{k})>0 \quad \eta_{s}(R(\bar{k})) \geq 0 \quad \eta_{R}(\bar{k})<0
$$

Hence, it is clear that the dynamics with full employment $\left(\eta_{L}(\bar{k})=0\right)$ is monotonic, $d(\bar{k})>0$, and that a steady state is locally stable if, and only if, the 


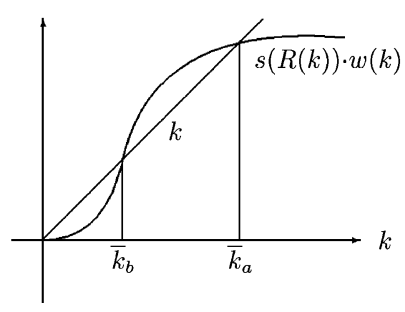

(a) $0<\sigma<1$

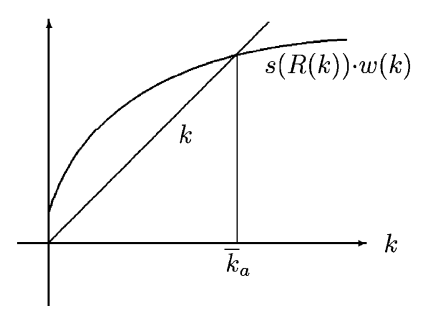

(b) $\sigma>1$

Figure 2 Long-run equilibrium

stability condition

$$
\eta_{w}(\bar{k})<1-\eta_{s}(R(\bar{k})) \eta_{R}(\bar{k})
$$

is satisfied. In particular, for a CES production function this condition is satisfied at the unique positive steady state when $\sigma \geq 1$ and it is satisfied at the larger of the two positive steady states if $\sigma<1$.

In the dynamics with unemployment (9), stability depends crucially on the elasticity of the employment function $L$. For a CES production function, Figure 1a tells us that $\eta_{L}(\bar{k})>0$ if $\sigma<1$. Proposition 2 below shows that such a steady state is stable if and only if it is stable in the competitive model, i.e. whenever the stability condition (13) is satisfied. Thus, the larger of the two steady states $\left(\bar{k}_{a}\right.$ in Figure $\left.2 \mathrm{a}\right)$ is locally stable also in the unemployment dynamics. When $\sigma>1$, there exists a unique steady state which can be of two different types, as indicated in Figure $1 \mathrm{~b}$. Either it is at $k_{1}$ at which the curve (8) cuts (6) from above, implying $\eta_{L}\left(k_{1}\right)>-1$, or (8) cuts (6) from below as at $k_{2}$, which implies $\eta_{L}\left(k_{2}\right)<-1$. Both such situations are possible, depending on technology, utility and labour market parameters. However, whenever the interest elasticity of savings is less than one, it emerges that a steady state at $k_{2}$ cannot be stable, whereas a steady state at $k_{1}$ may be stable or unstable. Denoting by $\sigma(k)$ the elasticity of substitution at $k$, we have

Proposition 2. Suppose that $\eta_{s}(R(\bar{k}))<1$.

(i) If $\eta_{L}(\bar{k})<-1$ and $\sigma(\bar{k})>1$, then $\bar{k}$ is unstable.

(ii) If $\eta_{L}(\bar{k})>-\frac{1}{2}$, then $\bar{k}$ is stable if and only if (13) is satisfied.

(iii) In particular, if the production function has CES $\sigma<1$, then $\bar{k}_{a}$ is stable and $\bar{k}_{b}$ is unstable, as they are in the competitive model. If $\sigma \geq 1$, then the unique positive steady state $\bar{k}_{a}$ is locally stable if $\eta_{L}\left(\bar{k}_{a}\right)>-\frac{1}{2}$ and the steady state is unstable if $\eta_{L}\left(\bar{k}_{a}\right)<-1$.

Proof. See the Appendix.

Four remarks are worth making. First, the proposition does not answer whether in the case $\sigma>1$ a steady state with $-1<\eta_{L}(\bar{k})<-\frac{1}{2}$ is stable or not 
(which may be the case at $k_{1}$ in Figure 1). Suppose that savings are independent of the interest rate $\left(\eta_{s}(R(k))=0\right)$. Stability of the steady state then requires that $d(\bar{k})>-1$, which means that $\eta_{w}(\bar{k})+2 \eta_{L}(\bar{k})+1>0$. Since $\eta_{w}(\bar{k})<1$ because of (16) and $\sigma>1$, this condition is fulfilled if $\eta_{L}(\bar{k})$ is close to $-\frac{1}{2}$, but it is certainly not fulfilled if $\eta_{L}(\bar{k})$ is close to -1 . Furthermore, even if the steady state is locally stable, convergence to the steady state can be cyclical (this is also possible if $\left.\eta_{L}(\bar{k})>-\frac{1}{2}\right)$. Moreover, endogenous cycles can exist. ${ }^{9}$ Thus, in our overlapping-generations model with unemployment, steady states may be unstable if capital and labour are gross substitutes (and, moreover, dated consumption goods are gross substitutes in the intertemporal utility function). This contrasts with other results in the literature which find bifurcations and endogenous cycles in overlapping-generations economies only if there is either complementarity in utility (e.g. Grandmont, 1985) or in production (e.g. Grandmont et al., 1998).

Second, the stability analysis is not confined to the overlapping-generations model of Diamond with two-period lives. In the Solow growth model and in the OLG model with stochastic lives of Benassy (1997), capital accumulates according to $K_{t+1}=(1-\delta) K_{t}+s F\left(K_{t}, L_{t}\right)$ with some $0<\delta, s<1 .{ }^{10}$ If our labour market equilibrium is embedded in this model the dynamic equation (9) changes to

$$
k_{t+1} L\left(k_{t+1}\right)=L\left(k_{t}\right)\left((1-\delta) k_{t}+s f\left(k_{t}\right)\right)
$$

Again it turns out that a steady state of the competitive (full employment) Solow model coincides with a steady state of the unemployment model which is again independent of labour market conditions. ${ }^{11}$ The derivative (12) is replaced by

$$
d(\bar{k})=\frac{d k_{t+1}}{d k_{t}}(\bar{k})=\frac{1-\delta+\delta \eta_{f}(\bar{k})+\eta_{L}(\bar{k})}{1+\eta_{L}(\bar{k})}
$$

9. By the flip bifurcation theorem, a cycle of order 2 exists close to a bifurcation point at which $d(\bar{k})=-1$ (a set of parameters close to a bifurcation point is $\sigma=1.5, A_{K}=A_{L}=100, \alpha=0.3$, $\lambda=0.6, \beta=0.3, \pi=0.1, s=0.2$ ). Simulation studies suggest, however, that such bifurcations are subcritical, i.e. an unstable cycle coexists with a stable steady state (corridor stability).

10. In the model of Benassy (1997) (which is based on Huffman, 1993), households work only in the first period of their lives and receive capital income in all future periods. A constant probability of death in each period and logarithmic preferences imply that savings are a constant fraction of aggregate income, as in the Solow model. Our labour market equilibrium can be embedded in this model in the same way as in the standard Diamond model with two-period lives.

11. We are grateful to a referee for pointing out that the Solow model with CES technology and $\sigma>1$ can exhibit an endogenous growth equilibrium with $k_{t} \rightarrow \infty$, as opposed to the overlapping-generations model (see Jones and Manuelli, 1992). As our analysis in Section 3 shows, such a balanced-growth path would exist in the Solow model augmented by unemployment only when $\sigma>\bar{\sigma}$ is satisfied (otherwise, the unique equilibrium has $L(k)=0$ ). In this case, employment is permanently falling along the balanced-growth path. 
One easily checks that the steady state is stable if $\eta_{L}(\bar{k})>-\frac{1}{2}$ and unstable if $\eta_{L}(\bar{k})<-1$. Hence Proposition 2 applies also to this model, but additional assumptions about the savings elasticity or about the elasticity of $w(k)$ are not required, since the first is zero by assumption and since savings are a constant fraction of total income, and not just of labour income as in the Diamond model.

Third, why does the correspondence between the competitive and the unemployment model break down if preferences are non-homothetic? With an arbitrary intertemporal utility function, savings and indirect utility are functions of the expected return and of first-period income, $s\left(R_{t+1}, I_{t}\right)$ and $v\left(R_{t+1}, I_{t}\right)$, but savings are non-linear in income and the indirect utility function is no longer multiplicative. A first consequence is that the expected return enters the objective function of trade unions in a non-trivial way, so that the bargaining solution depends on $R_{t+1}=R\left(k_{t+1}\right)$. Hence, short-run employment is now a function $L\left(k_{t}, k_{t+1}\right)$. The second consequence is that savings rates of employed and unemployed persons differ because savings are non-linear in income. Therefore, instead of (9), we obtain

$$
\begin{aligned}
k_{t+1} L\left(k_{t+1}, k_{t+2}\right)= & s\left(R\left(k_{t+1}\right), w\left(k_{t}\right)\left(1-\tau_{t}\right)\right) L\left(k_{t}, k_{t+1}\right) \\
& +s\left(R\left(k_{t+1}\right), \lambda w\left(k_{t}\right)\left(1-\tau_{t}\right)\right)\left(1-L\left(k_{t}, k_{t+1}\right)\right)
\end{aligned}
$$

where $\tau_{t}=\tau\left(k_{t}, k_{t+1}\right)$ is adjusted such that the government's budget is balanced, $\tau_{t} w\left(k_{t}\right) L\left(k_{t}, k_{t+1}\right)=\lambda\left(1-\tau_{t}\right) w\left(k_{t}\right)\left(1-L\left(k_{t}, k_{t+1}\right)\right)$. Equation (14) now defines a two-dimensional system, whereas the competitive Diamond model (in which all persons are employed and receive the same wage) is still described by the usual one-dimensional dynamics $k_{t+1}=s\left(R\left(k_{t+1}\right), w\left(k_{t}\right)\right)$. Obviously, steady-state solutions of both models differ in general.

Finally, the fact that steady-state capital intensities of our bargaining set-up coincide with those of the benchmark economy with perfectly competitive labour markets depends strongly on our assumption that the budget of the unemployment insurance is always balanced by appropriate taxation of wage income. In a companion paper (Kaas and von Thadden, 2001), we relax this assumption and discuss how the possibility of bond financing leads to additional steady states and much richer (two-dimensional) dynamics.

\section{EFFECTS OF WAGE PRESSURE}

To illustrate how sensitively the dynamic behaviour of our economy depends on the magnitude of $\sigma$, we return now to the CES specification introduced in Section 3. Suppose that the economy is initially in a steady state which is stable under full employment dynamics $\left(\bar{k}_{a}\right.$ in Figure 2$)$ and consider an adverse shock to wage setting which is, for instance, induced by stronger power of unions in wage negotiations (a fall in $\beta$ ) or by more generous payments of benefits (a higher replacement rate $\lambda$ ). As can be seen from (6) and (7), both such shocks shift the curve (6) downwards (a rise in $\lambda$ directly in

\section{8}


(6); a fall in $\beta$ by lowering $\mu$, which in turn reduces $L(k))$. Figures $1 \mathrm{a}$ and $1 \mathrm{~b}$ reveal that, irrespective of the size of $\sigma$, such shocks lead to lower employment and a higher capital intensity (and wages). Thus, the impact effect of an adverse shock to wage setting on employment is the same in both cases.

Suppose first that the shock is permanent. From Proposition 2, we know that for $\sigma<1$ the dynamics will always be (locally) stable. As shown in Figure 3, gross complementarity of inputs ensures that the initial decline in employment (move from $A$ to $B$ ) will be reinforced over time because of reduced capital formation on the way to the new steady state $C$. More specifically, while the capital intensity $k$ returns gradually over time to its initial value, the levels of employment and capital in the new steady state are permanently lower. As indicated by Proposition 2, for $\sigma>1$ it is indeed possible to find parametric constellations in which the same experiment turns out to be unstable. Yet, assume dynamics are stable. Again, in the long run the capital intensity remains unchanged, while employment and the capital stock are lower than in the initial situation. However, in contrast to the case $\sigma<1$, employment now overshoots on impact, since the ensuing process of reduced capital formation leads to a crowding-in of employment under gross substitutability.

Differences between the two regimes become even more pronounced if one considers a temporary shock to wage setting. The qualitative effects of such temporary shocks can be read off Figure 3 if one considers movements from $A$ over $B$ to $D$ back to $A$. To illustrate this in more detail, we present results from a stylized simulation exercise. In all simulations, we assume a Cobb-Douglas utility function, so that the savings rate is a constant and set equal to $s=0.14$. A positive interest elasticity of savings would generally amplify the response of capital to shocks, but qualitatively the results would be unchanged. Technology parameters are $A_{K}=A_{L}=20, \alpha=0.5$, labour market parameters

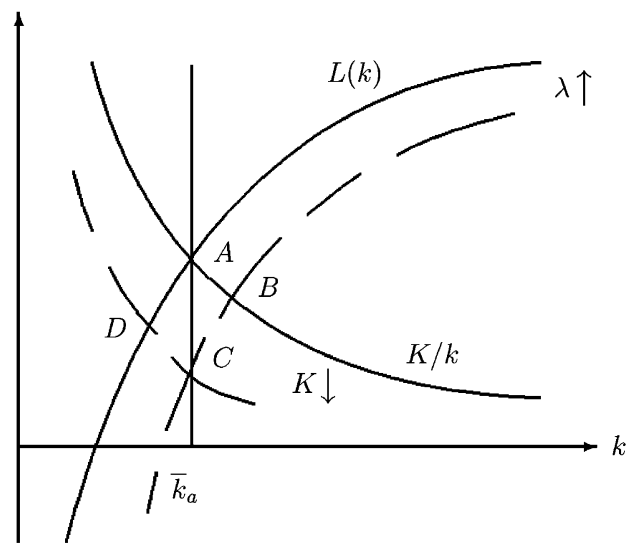

Figure 3 Dynamics $(0<\sigma<1)$ 
are $\lambda=0.6, \beta=0.3, \pi=0.1$. When $\sigma=0.5$, there is a stable steady state at about $k=3.297$ with unemployment rate 0.19 and labour share 0.77 . The simulation starts in period 1 at the steady state, and in period 5 there is a 10 per cent increase in the replacement ratio to $\lambda=0.66$, lasting three periods. From period 8 on, the replacement rate is back at 0.6. Figure 4 shows the adjustment paths of the unemployment rate and of the labour share (with the latter to be discussed below). In particular, unemployment dynamics exhibit some persistence, before unemployment gradually climbs back to its original value.

Figure 5 illustrates the same simulation exercise for $\sigma=2$. Note that unemployment overshoots first and falls temporarily even below its original value when the wage pressure is over, since now labour substitutes partly for the lower capital stock.
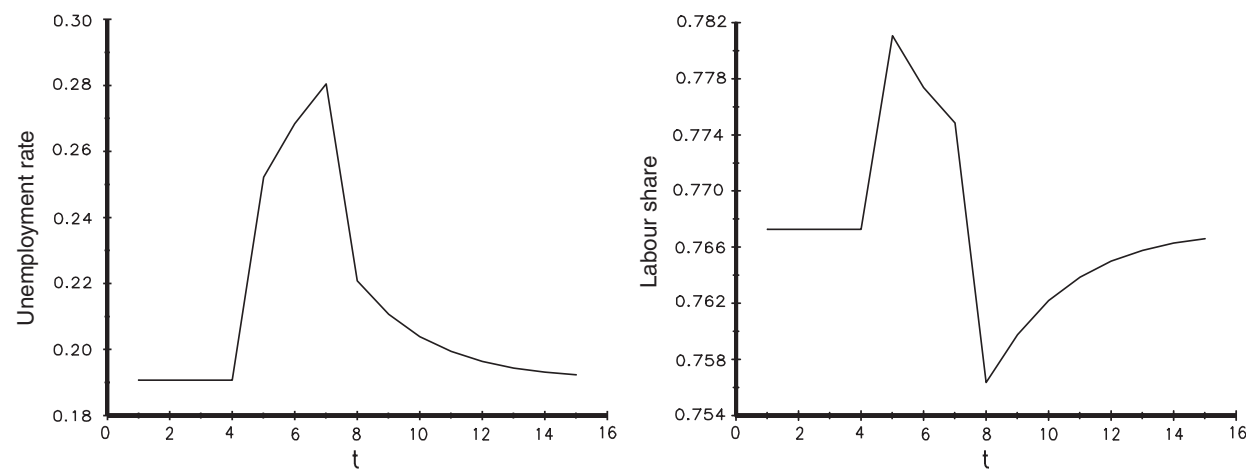

Figure 4 Temporary wage pressure: unemployment rate and labour share $(\sigma=0.5$, constant savings rate)
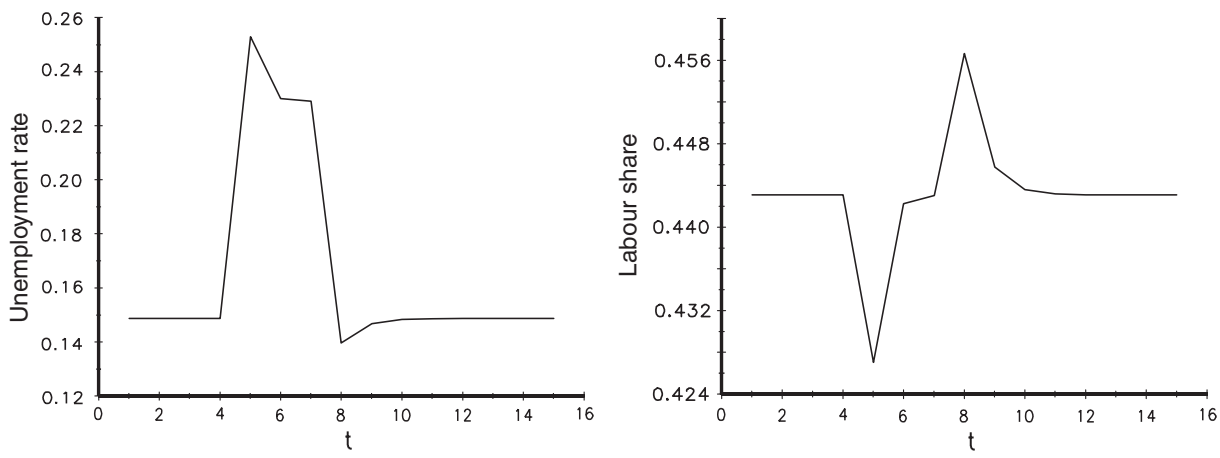

Figure 5 Temporary wage pressure: unemployment rate and labour share $(\sigma=2$, constant savings rate) 


\section{DISCUSSION}

(i) Addressing the evolution of unemployment and income shares in selected continental European countries over the past decades, Blanchard (1997, 1998) uses a framework in which, much as in our approach, the long-run capital intensity is independent of parameters describing a non-competitive labour market. ${ }^{12}$ As argued in detail by Blanchard, adverse labour market shocks may in isolation potentially explain the rise in unemployment, but not in combination with the observed evolution of income shares. The key finding reported by Blanchard is as follows. The early phase of (rising) unemployment in continental Europe beginning in the 1970s went hand-inhand with a rise in the labour share. Yet, since the mid-1980s the share of capital has improved again and reached levels even beyond those prevailing in the early 1970s, while unemployment kept rising. To account for this puzzling reversal of income shares, Blanchard considers the possibility of a gradually emerging technological bias against labour, i.e. a shift of the production function towards less labour-intensive production. ${ }^{13}$ Our discussion of the effects of wage pressure, if combined with a look at the implied evolution of income shares, shows that our set-up runs into similar difficulties in explaining the movements of income shares - irrespective of the magnitude of $\sigma$. As can be easily checked, for CES functions the labour share $w(k) / f(k)$ is decreasing (increasing) in the capital intensity if and only if $\sigma>1(\sigma<1)$. Correspondingly, if capital and labour are substitutes, the fall in employment after a wage-setting shock will be strong enough to overcompensate the rise in wages, implying on impact a fall in the labour share fall (Figure 5), which is not consistent with the evidence reported by Blanchard. By contrast, if $\sigma<1$, the labour share moves on impact in the appropriate direction. Yet, as one infers from Figure 3, after a permanent wagesetting shock, the labour share would gradually move back to its initial value. Thus, to account for the observed decline of the labour share since the mid1980 s below its initial level, it would be more appropriate to consider a temporary wage-setting shock (Figure 4). However, this 'exercise' would be at odds with the observation that unemployment stayed at high levels. ${ }^{14}$

12. However, his analysis differs from ours in several ways. First, Blanchard considers a constant, exogenously given interest rate. Second, firms are subject to adjustment costs when choosing their inputs. Third, the labour supply of the economy is approximated at the aggregate level by a wage-setting relationship which asserts a negative relationship between the real wage and the unemployment rate. Fourth, Blanchard also considers imperfections in the output market which we specify as being perfectly competitive.

13. For further empirical evidence on shifts in income shares, see Bentolila and Saint-Paul (1999). For detailed evidence on the German economy, supporting the broad picture given by Blanchard, see the empirical findings in Deutsche Bundesbank (2001).

14. In the more detailed working paper version of this paper, downloadable from the Bundesbank's web page, we can confirm that technological changes can indeed be an explanation for this puzzle if we reproduce a shock as assumed by Blanchard in the context of our model. 
(ii) The dependence of virtually all our results on the elasticity of substitution between labour and capital raises the question of how to appropriately specify the technological set-up in an aggregate framework. The concept of a production function with undated inputs suggests that the entire capital stock can be freely combined with all available units of labour. Yet, as discussed at large in the literature on 'putty-clay' aspects of technology, this notion is misleading since the embodiment of technology in the capital stock limits ex-post substitution possibilities once investments have been made (see Caballero and Hammour, 1998). In a recent study on various OECD countries, Andersen et al. (1999) address thoroughly the misspecification problem if estimates for the elasticity are directly obtained from a standard 'putty-putty' framework. Allowing for long adjustment lags in an error correction specification, the study recovers for all countries values of the elasticity well below unity. Findings of this type are also reported in Rowthorn (1999), who gives a broad review of the empirical literature on this issue. However, deviating evidence for France and Germany is given by Berthold et al. (1999), who use an error-correction model and estimate values of $\sigma$ significantly above unity. Similarly, the assumptions made in the theoretical literature are also inconclusive: Benassy (1997), Rowthorn (1999) and Acemoglu (2000), for example, confine themselves to values below unity. Daveri and Tabellini (2000), Hansen (1999) and the widely cited textbook by Layard et al. (1991) maintain the assumption of a unit elasticity. Blanchard (1997, 1998) considers scenarios for $\sigma=1$ and $\sigma=2$, although, as mentioned above, the implications of this assumption are different from ours due to the explicit introduction of adjustment costs.

Taken at face value, an overlapping-generations economy with two-period lived agents seems not to be the ideal framework to address this debate. However, to make our model more compelling in the putty-clay context, one could simply assume that firms learn the realization of some shock describing the state of technology only after investments in unspecific capital have been made. More importantly, recall from Section 4 that our results apply also, for example, in the context of a standard Solow growth model. In summary, given the evolution of income shares and the pronounced persistence in observed time series on unemployment, the predictions of our model for $\sigma>1$ are not particularly plausible. Complementing empirical studies on puttyclay aspects of technology, our analytical findings rather suggest that values of $\sigma<1$ have more reasonable properties if one uses a standard production function with undated inputs.

\section{CONCLUSION}

This paper presents a dynamic general equilibrium framework to address the endogenous response of capital to wage-setting or technology shocks as an important propagation mechanism for persistent employment dynamics. We 
augment an otherwise standard overlapping-generations economy by a rightto-manage bargaining structure. Using the outcomes of a model with perfectly competitive labour markets as a benchmark, we show that under wage bargaining the existence, uniqueness and stability of equilibria depend sensitively on the magnitude of the elasticity of substitution between labour and capital. Values of the elasticity below unity tend to preserve stability and lead to empirically plausible responses of employment and income shares to wage-setting shocks. By contrast, for values of the elasticity above unity the response pattern to such shocks is less plausible, and, more fundamentally, long-run stationary equilibria may well become unstable. We demonstrate that our results are not confined to the special structure of overlappinggenerations economies, but apply also, for example, in the context of a standard Solow model when augmented correspondingly by wage bargaining. Thus, given the broad range of estimates of the substitution elasticity presented in the empirical literature, our results give some guidance for this debate from a theoretical perspective.

\section{APPENDIX}

\section{Proof of Proposition 2}

(i) Notice that the elasticity of substitution is

$$
\sigma(k)=-\left(\frac{d\left(f^{\prime}(k) / w(k)\right)}{d k}\right)^{-1} \frac{f^{\prime}(k) / w(k)}{k}=\frac{\eta_{f}(k)-1}{n_{f^{\prime}}(k)}
$$

and that

$$
\eta_{w}(k)=\frac{\eta_{f}(k)}{\sigma(k)}
$$

Now $\eta_{w}(\bar{k})<1$ since $\eta_{f}(\bar{k})<1$ and $\sigma(\bar{k})>1$. Hence the numerator in (12) is negative. If the denominator is also negative, $\bar{k}$ is unstable since $d(\bar{k})>1$ because of $\eta_{w}(\bar{k})<1-\eta_{s}(R(\bar{k})) \eta_{R}(\bar{k})$. If the denominator is positive, suppose that $\bar{k}$ is stable, so that $d(\bar{k})>-1$ which means

$$
\eta_{w}(\bar{k})+2 \eta_{L}(\bar{k})+1>\eta_{s}(R(\bar{k})) \eta_{R}(\bar{k})
$$

Since $\eta_{L}(\bar{k})<-1$ and since $\eta_{R}(\bar{k})=\eta_{f^{\prime}}(\bar{k}) f^{\prime}(\bar{k}) /\left(f^{\prime}(\bar{k})+1-\delta\right) \geq \eta_{f^{\prime}}(\bar{k})$, this implies $\eta_{s}(R(\bar{k}))>\eta_{f^{\prime}}(\bar{k})^{-1}\left(\eta_{w}(\bar{k})-1\right)$. Using (A.1) and (A.2) yields

$$
\eta_{s}(R(\bar{k}))>\frac{\sigma(\bar{k})}{\eta_{f}(\bar{k})-1} \cdot \frac{\eta_{f}(\bar{k})-\sigma(\bar{k})}{\sigma(\bar{k})}=\frac{\sigma(\bar{k})-\eta_{f}(\bar{k})}{1-\eta_{f}(\bar{k})}>1
$$

a contradiction to the assumption that $\eta_{s}(R(\bar{k}))$ does not exceed one.

(ii) Under the assumptions, the denominator of (12) is clearly positive. Suppose that $\bar{k}$ is locally stable. Then $d(\bar{k})<1$ implies (13). Now suppose that 
(13) is satisfied. Then, if the numerator of (12) is non-negative, the steady state is locally stable since $0 \leq d(\bar{k})<1$. If the numerator is negative, $\bar{k}$ is locally stable if $d(\bar{k})>-1$ which is equivalent to (A.3). But since the right-hand side of this inequality is non-positive, and since $\eta_{L}(\bar{k})>-\frac{1}{2}$, this condition is fulfilled. Hence $\bar{k}$ is stable if and only if (13) is satisfied.

(iii) If $\sigma \geq 1,(13)$ is satisfied at the unique steady state. Hence, according to (ii), this steady state is stable if $\eta_{L}(\bar{k})>-\frac{1}{2}$ and according to (i) it is unstable if $\eta_{L}(\bar{k})<-1$. If $\sigma<1, \eta_{L}(\bar{k})>0$, and according to (ii) a steady state is stable iff (13) is satisfied, which is the case at $\bar{k}_{a}$ but not at $\bar{k}_{b}$.

\section{ACKNOWLEDGEMENTS}

We wish to thank, without implicating them, two anonymous referees, Ansgar Belke, Rainer Fehn, Heinz Herrmann and Johannes Hoffmann, as well as seminar participants in Vienna, in Tübingen, at the Bundesbank, at the 3rd Kiel Workshop on Growth and European Labour Markets and the 2nd ECB Labour Market Workshop for helpful comments. The views expressed in this paper are those of the authors and do not necessarily reflect the views of the Deutsche Bundesbank.

Address for correspondence: Leopold von Thadden, Deutsche Bundesbank, Economic Research Centre, Wilhelm-Epstein-Strasse 14, Germany. Tel.: +4969 9566 2730; e-mail: leopold.von-thadden@bundesbank.de

\section{REFERENCES}

Acemoglu, D. (2000), 'Labour- and Capital-Augmenting Technical Change', NBER Working Paper No. 7544.

Andersen, P., M. Klau and E. Yndgaard (1999), 'Higher Profits and Lower Capital Prices: Is Factor Allocation Optimal?', BIS Working Paper No. 65.

Azariadis, C. (1993), Intertemporal Macroeconomics, Basil Blackwell, New York.

Bean, C. (1989), 'Capital Shortages and Persistent Unemployment', Economic Policy 8, 11-53.

Benassy, J.-P. (1997), 'Imperfect Competition, Capital Shortages and Unemployment Persistence', Scandinavian Journal of Economics 99(1), 15-27.

Bentolila, S. and G. Saint-Paul (1999), 'Explaining Movements in the Labour Share', CEMPI Working Paper No. 9905.

Berthold, N., R. Fehn and E. Thode (1999), 'Falling Labour Share and Rising Unemployment: Long-Run Consequences of Institutional Shocks?', Working paper, Universität Würzburg.

Blanchard, O. (1997), 'The Medium Run', Brookings Papers on Economic Activity 2, 89158.

Blanchard, O. (1998), 'Revisiting European Unemployment: Unemployment, Capital Accumulation and Factor Prices', NBER Working Paper No. 6566.

Burda, M. (1988), 'Is there a Capital Shortage in Europe?', Weltwirtschaftliches Archiv 124, 38-57. 
Caballero, R. and M. Hammour (1998), 'Jobless Growth: Appropriability, Factor Substitution, and Unemployment', Carnegie-Rochester Conference Series on Public Policy 48, 51-94.

Calmfors, L. and J. Drifill (1988), 'Bargaining Structure, Corporatism, and Macroeconomic Performance', Economic Policy 6, 13-62.

Daveri, F. and G. Tabellini (2000), 'Unemployment and Taxes', Economic Policy 15, 47104.

Deutsche Bundesbank (2001), 'Factor Prices, Employment and Capital Stock in Germany: Results of a Simulation Study', Monthly Report, July, 49-61.

Devereux, M. and B. Lockwood (1991), 'Trade Unions, Non-Binding Wage Agreements, and Capital Accumulation', European Economic Review 35, 1411-1426.

Galor, O. and H. Ryder (1989), 'Existence, Uniqueness, and Stability of Equilibrium in an Overlapping Generations Model with Productive Capital', Journal of Economic Theory 49, 360-375.

Grandmont, J. M. (1985), 'On Endogenous Competitive Business Cycles', Econometrica 53, 995-1045.

Grandmont, J. M., P. Pintus and R. de Vilder (1998), 'Capital-Labor Substitution and Competitive Nonlinear Endogenous Business Cycles', Journal of Economic Theory 80, $14-59$.

Grout, P. (1984), 'Investment and Wages in the Absence of Binding Contracts: A Nash Bargaining Approach', Econometrica 52, 449-460.

Hansen, C. (1999), 'Long-Run Impact of Increased Wage Pressure', Journal of Economics 69(2), 141-157.

Huffman, G. W. (1993), 'An Alternative Neo-Classical Growth Model with ClosedForm Decision Rules', Economics Letters 42, 59-63.

Jones, L. E. and R. E. Manuelli (1992), 'Finite Lifetimes and Growth', Journal of Economic Theory 58, 171-197.

Kaas, L. and L. von Thadden (2001), 'Budgetary Policy and Unemployment Dynamics', Discussion Paper No. 07/01, Economic Research Centre of the Deutsche Bundesbank.

Layard, R., S. Nickell and R. Jackman (1991), Unemployment, Macroeconomic Performance and the Labour Market, Oxford University Press, Oxford.

McDonald, I. and R. Solow (1981), 'Wage Bargaining and Employment', American Economic Review 71(5), 896-908.

Oswald, A. (1985), 'The Economic Theory of Trade Unions: An Introductory Survey', Scandinavian Journal of Economics 87(2), 160-193.

Pissarides, C. (1998), 'The Impact of Employment Tax Cuts on Unemployment and Wages: The Role of Unemployment Benefits and Tax Structure', European Economic Review 42, 155-183.

Rowthorn, R. (1999), 'Unemployment, Wage Bargaining and Capital-Labour Substitution', Cambridge Journal of Economics 23, 413-425.

Van der Ploeg, F. (1987), 'Trade Unions, Investment and Employment: A NonCooperative Approach', European Economic Review 31, 1465-1492. 